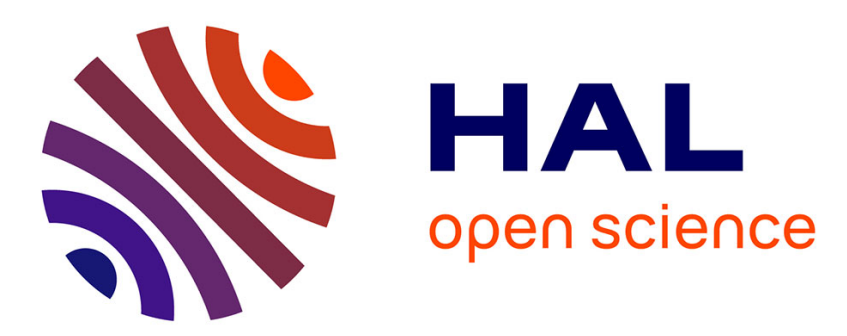

\title{
Study, by neutron small angle scattering, of addition of an electrolyte to reversed micellar solution \\ C. Cabos, P. Delord
}

\section{To cite this version:}

C. Cabos, P. Delord. Study, by neutron small angle scattering, of addition of an electrolyte to reversed micellar solution. Journal de Physique Lettres, 1980, 41 (18), pp.455-458. 10.1051/jphyslet:019800041018045500 . jpa-00231820

\section{HAL Id: jpa-00231820 https://hal.science/jpa-00231820}

Submitted on 1 Jan 1980

HAL is a multi-disciplinary open access archive for the deposit and dissemination of scientific research documents, whether they are published or not. The documents may come from teaching and research institutions in France or abroad, or from public or private research centers.
L'archive ouverte pluridisciplinaire HAL, est destinée au dépôt et à la diffusion de documents scientifiques de niveau recherche, publiés ou non, émanant des établissements d'enseignement et de recherche français ou étrangers, des laboratoires publics ou privés. 


\title{
Study, by neutron small angle scattering, of addition of an electrolyte to reversed micellar solution
}

\author{
C. Cabos and P. Delord \\ Groupe de Dynamique des Phases Condensées $\left({ }^{*}\right)$, Laboratoire de Minéralogie Cristallographie, \\ U.S.T.L., Place E.-Bataillon, 34060 Montpellier Cedex, France
}

(Reçu le 9 avril 1980, révisé le 15 juillet, accepté le 21 juillet 1980)

\begin{abstract}
Résumé. - Nous étudions l'influence d'un sel sur la dimension des micelles inverses du système ternaire Aérosol OT-heptane-eau par diffusion centrale des neutrons.

L'augmentation de la taille des micelles est clairement mise en évidence.

Le modèle sphérique paraît être le meilleur pour représenter la micelle.
\end{abstract}

\begin{abstract}
We study the part played by an added salt upon the size of reversed micelles of the ternary system Aerosol OT-n-heptane-water by small angle neutron scattering.

The growth of the micellar size is clearly shown.

The spherical model seems to be the best for the description of the micelle.
\end{abstract}

1. Introduction. - Aerosol OT (Na di 2 ethylhexylsulfosuccinate) is a surfactant, highly soluble in hydrocarbon substances, which may give reversed micelles in the presence of water.

In the $L_{2}$ phase of such a ternary system, Na counterions and water make up the aqueous core surrounded by the polar heads of the amphiphilic ions the hydrophobic chains of which are diping in the hydrocarbon substance (here $\mathrm{n}$-heptane). This system shows some analogy with water-in-oil microemulsions but in this case, no cotensioactive substance is necessary to solubilize large amounts of water.

Micellar solutions of Aerosol OT have been recently studied by other methods : light scattering and ultracentrifuge measurements [1], fluorescence polarization technique [2], photon correlation spectroscopy [3], viscosity and dynamic light scattering methods [4], viscosity and electrical birefringence relaxation [5].

We have previously studied this system without salt by small angle neutron scattering [6]. Contrast variation methods, with intensity standardization by comparison with a known particle [7] allows us to determine important characteristics of the micelle (molar volume, aggregation number $n, \sigma$ polar head area at the water-oil interface).

Salt adding modifies physicochemical properties

(*) Laboratoire Associé au C.N.R.S. of the middle [8]. There is a lowering of the water maximal solubility and of the relative viscosity. These results may be explained for a chosen value $\omega$ of the water-to-AOT molar ratio by the formation of spherical micelles of higher size together with a polar head area lowering. This interpretation based upon geometric reasons may be quantitatively verified by small angle neutron scattering.

2. Experimental studies. - Aerosol OT is a Fluka reagent used with further purification by the method of Rogers and Windsor [9].

2.1 Solutions. - Two kinds of micellar AOTbrine-n-heptane have been studied for $\omega=8$ and $\omega=15$. For each $\omega$ value, two salt $(\mathrm{NaCl})$ concentrations have been studied. For each salt concentration, two solutions $\left(C_{1}=12 \mathrm{mg} / \mathrm{ml}, C_{2}=20 \mathrm{mg} / \mathrm{ml}\right)$ have been prepared. All experiments are performed at $20^{\circ} \mathrm{C}$.

2.2 EXPERIMENTAL APPARATUS. - All the experiments have been performed on the D11 apparatus in the Institute Laue-Langevin; $I(q)$ measures, where $q=4 \pi \frac{\sin \theta}{\lambda}$, are performed in the Guinier zone $\left(q R_{\mathrm{G}}<1\right)$. The measurement of the radius of gyration $R_{\mathrm{G}}$ and of $I(0)$ is achieved by extrapolation to zero momentum transfer and to zero concentration of the micelles. 
2.3 CONTRAST VARIATION METHOD. - Various deuteration rates of the water, allow us to determine $V_{\mathrm{w}}$ the aqueous core volume of the particle [6] ; the square root zero angle intensity is a linear function of the scattering length density of the internal water and the slope of the graph $[I(0) / c]^{1 / 2}$ is proportional to

$$
\left(\frac{n \omega^{2} \vartheta_{\mathrm{W}}^{2}}{m_{\mathrm{AOT}}+m_{\mathrm{W}} \omega}\right)^{1 / 2}
$$

$\vartheta_{\mathrm{W}}$ is the molecular volume of water ;

$m_{\mathrm{AOT}}$ is the molar mass of AOT $-m_{\mathrm{W}}$ the molar mass of water.

The knowledge of $n$ for $\omega=8$ and $\omega=15$ in AOT-water-heptane solutions allows us to determine $n$ for brine solutions. If $n_{1}, n_{2}, n_{3}$ are the aggregation numbers relative to the three studied solutions, for $\omega=8$ (or $\omega=15$ ) (Figs. $1 a$ and $1 b$ ), the ratio of the slope of the various straight lines allow us to calculate $\left(n_{1} / n_{2}\right)^{1 / 2}$ and $\left(n_{1} / n_{3}\right)^{1 / 2} ; n_{2}$ and $n_{3}$ being determined if the aggregation number without salt $n_{1}$ is known (ref. [6], table 1). The value of the radius of gyration is given by the slope $\alpha$ of the straight line $\operatorname{Ln}(I)$ versus $q^{2}$ by $R_{\mathrm{G}}^{2}=-3 \alpha$.

3. Results and discussion. - Figures $1 a$ and $1 b$ shown, for $\omega=8$ and $\omega=15$, the square root intensity $\left.\left[I(0), \rho_{0}\right) / c\right]^{1 / 2}$ after extrapolation to infinite dilution, versus $\rho_{0}$ the coherent scattering length density of micellization water. The $\mathrm{D}_{2} \mathrm{O}$ percentage in the $\mathrm{H}_{2} \mathrm{O} / \mathrm{D}_{2} \mathrm{O}$ mixtures is well known and $\rho_{0}$ is varying between $\rho_{\mathrm{H}_{2} \mathrm{O}}=-0.57 \times 10^{10} \mathrm{~cm}^{-2}$ and $\rho_{\mathrm{D}_{2} \mathrm{O}}=6.4 \times 10^{10} \mathrm{~cm}^{-2}$.

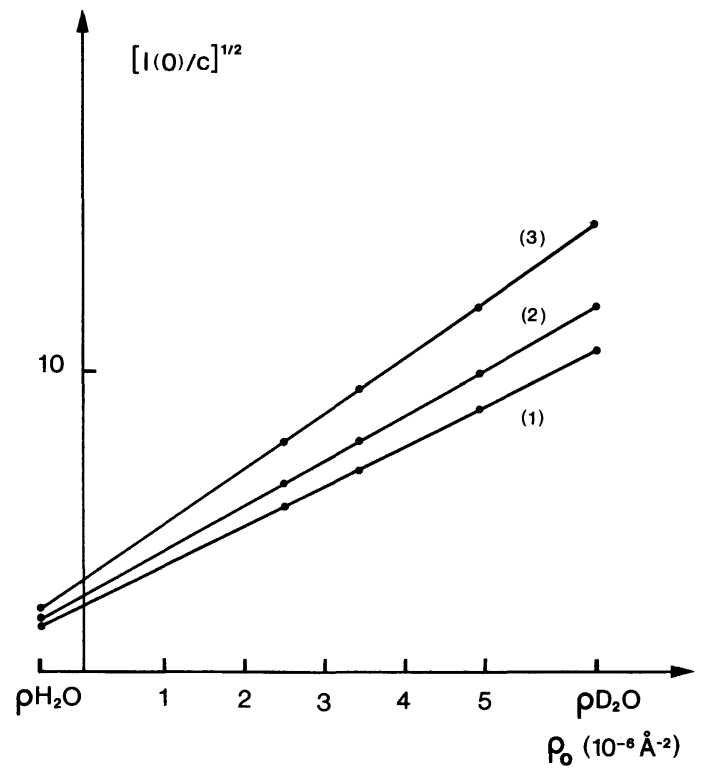

a)
The electrolyte presence in water may be neglected in a first approximation in the computation of $\rho_{0}$. Essentially, the $\mathrm{Na}^{+}$or $\mathrm{Cl}^{-}$ion number remains low in comparison with the number of water molecules which in practice determine the $\rho_{0}$ value; the table of experimental results give the $n$ value without salt [6] from which are deduced the $V_{\mathrm{w}}$ values for the two salt concentrations. We assume that the $\omega$ values are large enough in order to assume that the partial specific volume of water remains constant.

The accuracy of the results may be estimated from the uncertainty in the measurement of the slope of the straight line in figure 1 which is about $10 \%$ on $n$ and $V_{\mathbf{W}}$.

Figures $2 a$ and $2 b$ show the Guinier plots (Ln I versus $q^{2}$ ) of the particles containing only heavy water, from which the quoted radii of gyration have been obtained. In these conditions, the seen particle is, in a first approximation, an homogeneous droplet of $\rho_{\mathrm{D}_{2} \mathrm{O}}$ density diping in an uniform scattering length solvent [6].

Our experiment display a rapid growth of the aqueous core with salt adding.

Experimental results show that $R_{\mathrm{G}} \sqrt{5 / 3}$ is in good agreement with $\left(\frac{3 V_{\mathrm{w}}}{4 \pi}\right)^{1 / 3}$ and corroborate the validity of the spherical shape of the water droplet. The polar head area is defined by

$$
\sigma=\frac{1}{n}(4 \pi)^{1 / 3}\left(3 V_{\mathrm{w}}\right)^{2 / 3}
$$

and the aggregation number $n=36 \pi \omega^{2} \vartheta_{\mathrm{w}}^{2} / \sigma^{3}$ therefore $\sigma R=3 \mho_{\mathrm{W}} \omega\left(R=R_{\mathrm{G}} \sqrt{5 / 3}\right)$.

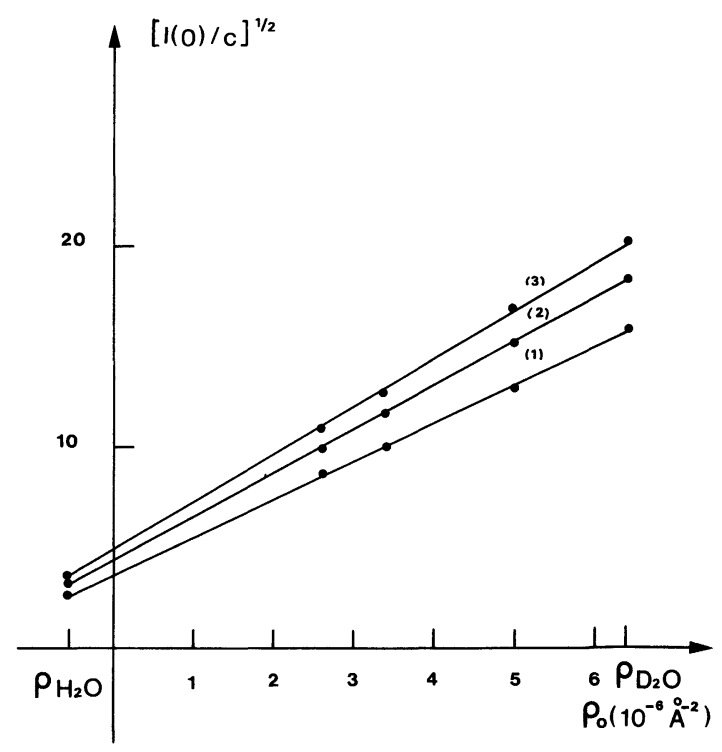

b)

Fig. 1. - The square root of $I(0) / c$ (in arbitrary unity) is - for a given value of the hydratation ratio - a linear function of the scattering length density of micellization water. The slope of the straight line gives the aqueous volume
a) $\omega=8\left\{\begin{array}{l}(1)[\text { salt }]=0 \\ \text { (2) [salt] }=0.2 \text { mole } .1^{-1} \\ \text { (3) [salt] }=0.4 \text { mole } .1^{-1}\end{array}\right.$
b) $\omega=15\left\{\begin{array}{l}(1)[\text { salt }]=0 \\ \text { (2) }[\text { salt }]=0.1 \text { mole } .1^{-1} \\ \text { (3) }[\text { salt }]=0.2 \text { mole } .1^{-1}\end{array}\right.$ 
Table I. - Experimental results.

\begin{tabular}{|c|c|c|c|c|c|c|c|c|}
\hline & $\begin{array}{c}\mathrm{NaCl} \\
\text { concentra- } \\
\text { tion } \\
\left(\text { mole. } 1^{-1}\right)\end{array}$ & $n$ & $V_{\mathrm{w}}\left(\AA^{3}\right)$ & $R_{\mathrm{G}} \sqrt{\frac{5}{3}}(\AA$ & $\left(3 V_{\mathrm{W}} / 4 \pi\right)^{1 / 3}$ & $\sigma\left(\AA^{2}\right)$ & $\begin{array}{c}\sigma R\left(\AA^{3}\right) \\
\text { (experimental) }\end{array}$ & $\begin{array}{l}3 v_{\mathrm{w}} \omega\left(\AA^{3}\right) \\
\text { (theoretical) }\end{array}$ \\
\hline \multirow{4}{*}{$\omega=8$} & - & - & - & & - & - & - & - \\
\hline & 0 & 115 & $2.75 \times 10^{4}$ & 19.0 & 18.7 & 38.0 & 722 & \multirow{3}{*}{720} \\
\hline & 0.2 & 150 & $3.56 \times 10^{4}$ & 20.4 & 20.4 & 34.9 & 712 & \\
\hline & 0.4 & 217 & $5.20 \times 10^{4}$ & 23.0 & 23.1 & 30.6 & 705 & \\
\hline \multirow{3}{*}{$\omega=15$} & 0 & 160 & $7.2 \times 10^{4}$ & 25.9 & 25.8 & 52 & 1347 & \multirow{3}{*}{1350} \\
\hline & 0.1 & 209 & $9.4 \times 10^{4}$ & 27.7 & 28.2 & 48 & 1325 & \\
\hline & 0.2 & 250 & $11.2 \times 10^{4}$ & 30.2 & 29.9 & 45 & 1359 & \\
\hline
\end{tabular}

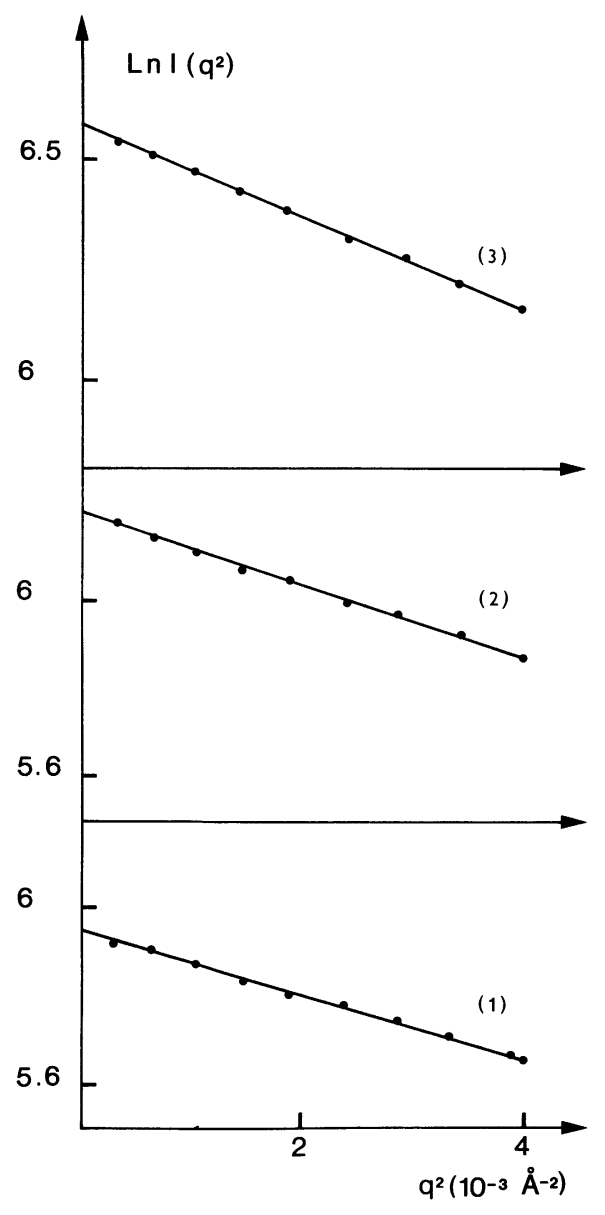

a)

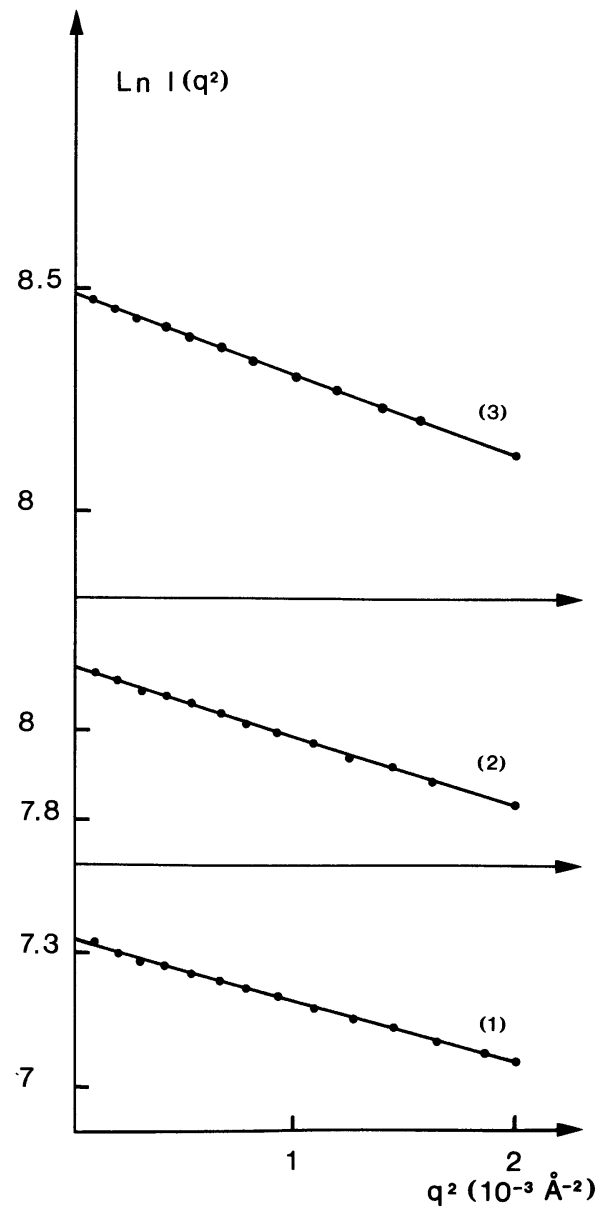

b)

Fig. 2. - Guinier plot of experimental curves.

a) $\omega=8\left\{\begin{array}{l}\text { (1) } R_{\mathrm{G}}=14.7 \AA \\ \text { (2) } R_{\mathrm{G}}=15.8 \AA \\ \text { (3) } R_{\mathrm{G}}=17.8 \AA\end{array} \quad\right.$ b) $\omega=15\left\{\begin{array}{l}\text { (1) } R_{\mathrm{G}}=20.1 \AA \\ \text { (2) } R_{\mathrm{G}}=21.5 \AA \\ \text { (3) } R_{\mathrm{G}}=23.4 \AA .\end{array}\right.$

4. Conclusion. - This study clearly shows the part played by added salt on the size of inverse micelles of Aerosol OT : a growth of the aqueous core with a correlative decrease of the area by polar head.
It is the first step of experimental and theoretical studies on the interaction between the electrostatic field within the inverse micelle and its charged boundary interface. 
Moreover, it proves that for dilute solutions the spherical model is the best one. This result seems to be inconsistent with relaxation experiments that display anisometric particles [8] but for more concentrated solutions. In our opinion, this fact may be explained by aggregation of micelles, dimer formation for example.

Experiments are in progress to test these various hypothesis.

\section{References}

[1] Eicke, H. F. and RehaK, J., Helv. Chim. Acta 59 (1976) 2883.

[2] Valeur, B. and KeH, E., J. Phys. Chem. 83 (1979) 3305.

[3] Zulauf, M. and Eicke, H. F., J. Phys. Chem. 83 (1979) 480.

[4] Day, R. A., Robinson, B. H., Clarke, J. H. R., Doherty, J. V., J. Chem. Soc. Faraday I. 75 (1979) 132.

[5] Rouvière, J., Couret, J. M., Lindheimer, M., Dejardin, J. L., Marrony, R., J. Chim. Phys. 76 (1979) 289.
[6] Cabos, C. and Delord, P., J. Appl. Crystallogr. 12 (1979) 502

[7] Cabos, C. and Delord, P., J. Physique 39 (1978) 432

[8] Rouvière, J., Couret, J. M., Lindheimer, A., Lindheimer, M., Brun, B., J. Chim. Phys. 76 (1979) 297.

[9] Rogers, J. and Windsor, P. A., J. Colloid Interface Sci. 30 (1969) 247. 